\title{
Inductor Design for High-Power Applications with Broad-Spectrum Excitation
}

\author{
Ian T. Wallace, Nasser H. Kutkut, Member, IEEE, Subhashish Bhattacharya, Student Member, IEEE, \\ Deepak M. Divan, Senior Member, IEEE, and Donald W. Novotny, Fellow, IEEE
}

\begin{abstract}
The design of high-power inductors for applications with broad current spectrum excitation is a challenging task. The resonant inductor of a resonant dc-link inverter (RDCLI) is one such example. The inductor current consists of a resonant current component, a dc component, which supplies the active power to the load and a modulation component, which depends on the modulation strategy. In addition, the frequency and amplitude of the dominant current components change with operating point. Conventional inductor designs for single-frequency excitation do not perform well in broad-spectrum applications. In order to improve these designs, the impact of broad current spectrums on winding design, core selection, power density, and thermalhandling capability must be investigated. In this paper, alternate inductor topologies, which better address the above issues, are proposed and investigated.
\end{abstract}

Index Terms - High-frequency magnetics, inductor design, resonant dc-link inverter, strip windings.

\section{INTRODUCTION}

$\mathbf{H}$ IGHER power inductors with broad current spectra present design challenges, which are not addressed by conventional design techniques. The integration of the electrical, mechanical, and thermal designs is not straightforward.

Conventional pulse-width-modulation (PWM) filter inductors are commonly designed using air cores or toroids of uniformly distributed air-gap materials and are wound with either litz wire or bare copper strands. These inductors are normally designed for single-frequency operation. Single-frequency operation enables an optimal design. For example, in constant switching frequency PWM inverters, the current harmonics are well known. This knowledge can be used to accurately select the inductor topology, core, and conductor size and shape.

In applications with broad-spectrum excitation, the current harmonics may not be precisely known. In addition, the amplitude and frequency of the current harmonics depend on the loading and the modulation strategy. Due to the high operating frequencies, special attention must be paid to limit ac winding and core losses. In addition, the presence of a significant dc component may lead to conflicting winding designs, especially with the use of litz wire. While litz wire can reduce high-frequency ac losses, its benefits are limited to a narrow frequency band and relatively low-current densities.

Manuscript received September 13, 1995; revised February 27, 1997. Recommended by Associate Editor, W. J. Sarjeant.

I. T. Wallace, N. H. Kutkut, and D. M. Divan are with Soft Switching Technologies, Middleton, WI 53562 USA (e-mail: ianw@softswitch.com).

S. Bhattacharya and D. W. Novotny are with the Department of Electrical and Computer Engineering, University of Wisconsin, Madison, WI 53706 USA.

Publisher Item Identifier S 0885-8993(98)00606-1.

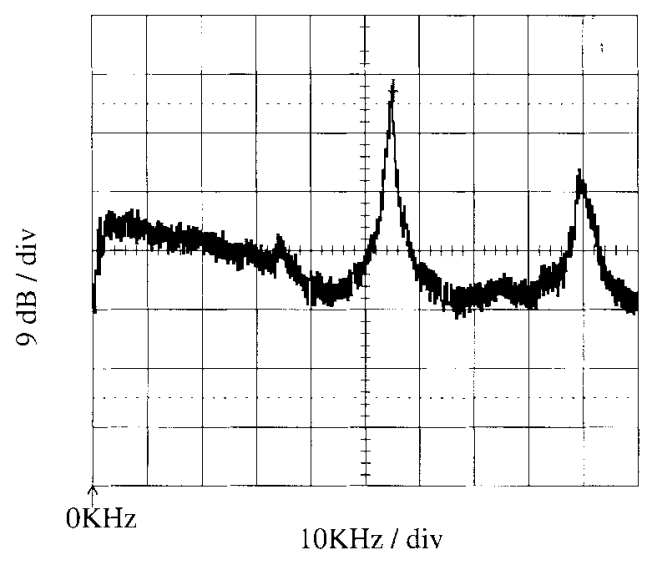

Fig. 1. Resonant inductor current spectrum at one operating point.

The issues governing inductors with broad-spectrum excitation and the drawbacks of the conventional design techniques in these applications are discussed in this paper. An alternate topology and winding arrangement, which is more suited to these applications, is proposed and analyzed. A case study for a $70-\mathrm{kW} 100-\mathrm{kHz}$ resonant dc-link inverter (RDCLI) inductor is presented, which compares its performance with conventional designs.

\section{DESIGN ISSUES FOR INDUCTORS WITH BROAD-SPECTRUM EXCITATION}

\section{A. Electrical Issues}

In applications such as the RDCLI, the inductor current spectrum ranges from dc up to the resonant frequency (70-100 $\mathrm{kHz}$ ). The RDCLI provides a resonating dc bus to allow zero voltage switching of the main devices [1], [2]. Due to a varying resonant bus frequency and discrete pulse modulation, the inductor current has a broad current spectrum (Fig. 1) [3].

Throughout the operating range of the converter, different spectral components dominate the inductor core and winding losses. At light loads, the resonant current component produces most of the losses, while at full load, the dc current component in the inductor, which can be five-ten times the resonant current, dominates the losses.

The multiple-frequency components in a broad spectrum make it difficult to estimate the core losses in a resonant inductor. As a first approximation, the designer could use the spectrum at one operating point to identify the main frequencies and use the data sheet information to estimate 


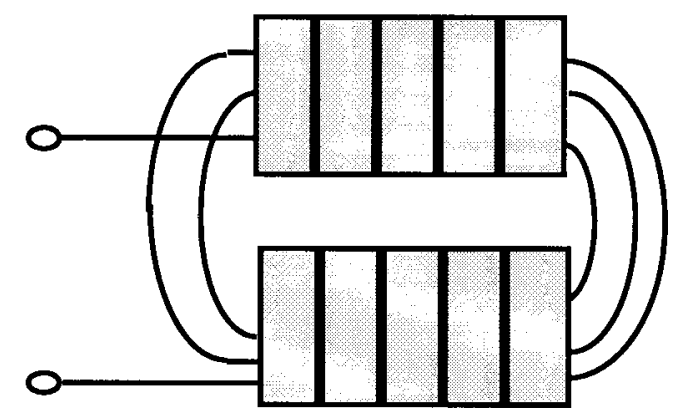

Fig. 2. Toroidal core wound with litz wire.

the losses. However, the current spectrum is nonstationary and the loss contributed by minor hysteresis loops change with the bias point [4]. Minor loop hysteresis losses are not provided by the manufacturer data sheets. In order to accurately estimate the losses, a good model of the material's hysteresis behavior under broad-spectrum excitation is needed. Lack of an appropriate dynamic model makes it harder to estimate core losses in such applications [5].

\section{B. Thermal Issues}

Most magnetic designs are thermally driven. Since inductors are commonly stressed to their thermal limit, improving the thermal-handling capability increases the power density and results in cost reduction. This can be achieved by any combination of the following: reducing the thermal-path resistance, providing large surface areas for cooling, and using topologies, which can be easily integrated with a heat sink.

\section{Mechanical Issues}

Finally, the mechanical design issues need to be incorporated with the electrical and thermal designs. The mechanical design issues include, simple winding arrangements, ease of manufacturability, ease of integration with heat sinks, and cold plates in addition to small size and weight.

\section{Conventional Inductor Designs}

Air core and toroidal core inductors with uniformly distributed air-gap material (low $\mu$ ) are commonly used in highpower applications. However, for applications rated at 30-250 $\mathrm{kW}$, an air core can take up to two-three times the volume compared to inductors designed with low $\mu$ material. In addition, the winding losses of an air-core inductor are high due to the large number of turns. The size and loss penalty make these designs unattractive in these applications. As a result, only toroidal designs will be considered. Fig. 2 shows an inductor with a toroidal core wound with litz wire. While there are some advantages to this topology there are many apparent drawbacks, which make it unsuitable for broadspectrum applications.

\section{A. Electrical Issues}

Litz wire is constructed to minimize high-frequency ac losses due to skin and proximity effects over a narrow frequency range. By insulating individual strands sized to about one skin depth and transposing the strands along the length of the wire, the copper is fully utilized resulting in a unity ratio of ac-dc resistance $\left(R_{\mathrm{ac}} / R_{\mathrm{dc}} \approx 1\right)$. However, to achieve these benefits, the conductor must be sized for the proper frequency range, and the resulting fine strands lead to a poor fill factor within the wire. Thus, a high-frequency litz wire does not have the cross-sectional area to conduct a large dc current. To increase the cross-sectional area, it is common to parallel windings. However, this further decreases the low-fill factor of litz wire. Therefore, increasing the current capacity by paralleling litz windings results in an increased core size and, hence, increased core losses.

With toroidal core inductors, the electrical design is straightforward. The number of turns and cores can be easily adjusted to obtain the desired inductance and flux density. However, uniformly distributed air-gap core materials (such as Arnold's MPP) that are suitable for high-power and high-frequency applications are expensive. On the other hand, lower cost uniformly distributed air-gap materials such as powdered iron have significantly higher losses.

\section{B. Thermal Issues}

A toroidal inductor wound with litz wire has poor thermal performance. Due to the insulation of individual strands, the thermal resistance of the windings is increased over bare copper. The copper is packaged in a bundle, which is enclosed within the core. This gives very low surface area per unit loss and dictates low-current densities. As a result, windings must be paralleled to reduce the current density to about $250 \mathrm{~A} / \mathrm{cm}^{2}$. However, this approach further reduces the effective surface area available for cooling.

\section{Mechanical Issues}

Toroidal cores do not allow easy integration with heat sinks or cold plates, which restricts the power density at high-power levels.

In conclusion, toroidal cores wound with litz wire are not suited to broad-spectrum applications due to the conductor design and thermal properties. In the following section, an alternate topology and winding is proposed, which overcomes some of these deficiencies.

\section{Alternate Topologies with Ferrite Cores}

Since the design of high-power inductors is thermally driven, alternate topologies, such as those shown in Fig. 3, become particularly attractive. The inductors shown below are designed using high-frequency ferrite cores with a lumped or distributed air gap to support the high mmf within the core. The windings are constructed with flat copper strips.

\section{A. Electrical Issues}

The choice of copper strips for broad current spectrum applications becomes very attractive. The copper strips allow high-current densities and provide a large surface area for cooling, eliminating the need for parallel windings. The ac winding losses can be optimized by properly sizing the strip 


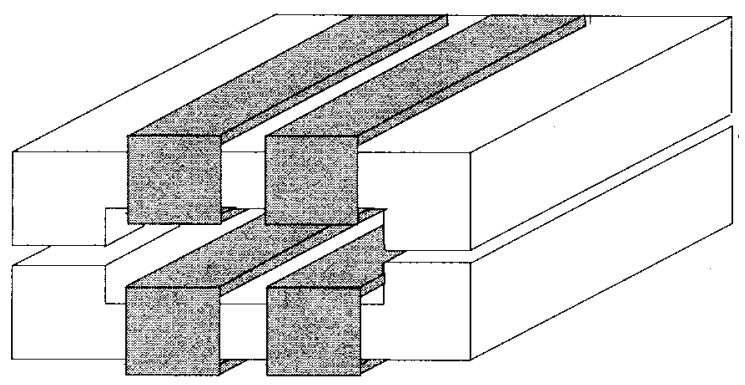

(a)

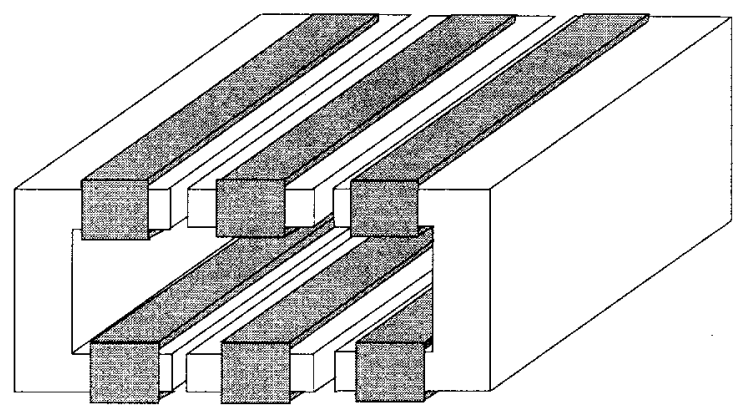

(b)

Fig. 3. Two possible ferrite-core inductors wound with copper strips.

conductors. A detailed discussion of the ac winding losses will be presented in the next section.

The use of ferrite cores results in lower core losses. Highfrequency ferrites, e.g., PC40, have lower loss per volume compared to uniformly distributed air-gap material such as MPP.

\section{B. Thermal Issues}

The main thermal advantage of this topology is the large copper surface area available for cooling. With forced cooling, the outer conductor surface does not have to be insulated, resulting in a low thermal-path resistance. Using a heat sink is another option, which can further improve the thermalhandling capability.

Since copper strips do not have the fill factor penalty associated with litz wire, the thermal penalty associated with paralleling litz wires to achieve low dc resistance is not an issue.

\section{Mechanical Issues}

Since there is no fill factor penalty with strip conductors, the window area can be made smaller, reducing the core size and weight. However, since ferrites have a lower saturation flux density compared with MPP cores, a slightly larger core volume is needed. This is offset by the higher cost associated with MPP cores.

The inductor topologies shown in Fig. 3 are easy to manufacture since they use readily available ferrite cores with strip copper windings. In addition, the structure can be easily integrated with a heat sink.

As discussed earlier, the proposed inductor topologies use discrete air gaps to support the high mmf within the core. The decision regarding whether to use lumped or distributed air

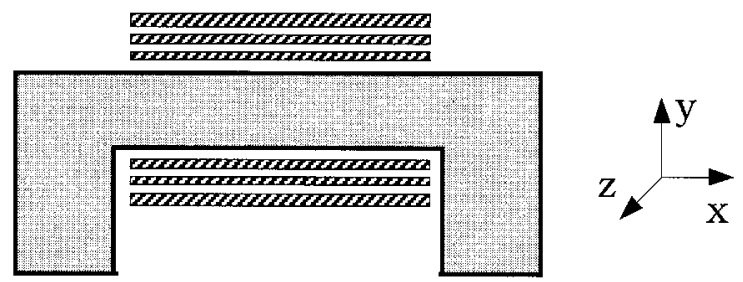

Fig. 4. Stacked winding design.

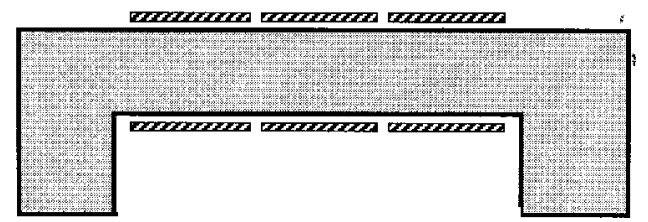

Fig. 5. Planar winding design.

gaps depends mainly on the effect of the gap on the winding losses.

In lumped gap designs, and in order to reduce the core size and weight, a low-profile core has to be used. However, care must be taken to insure that the fringing fields do not induce additional losses within the windings. This results in a minimum window height to keep these losses low.

Using distributed air-gap designs is also viable in these topologies. This allows the use of smaller air gaps distributed around the core and, hence, reduces the fringing fields [Fig. 3(b)]. However, the windings must be spaced away from the air gaps to reduce the losses caused by the fringing fields.

\section{Winding CONSTRUCTION FOR MULTITURN DESIGNS}

One of the main issues regarding the design of multiturn foil wound resonant inductors is the winding construction and layout. Two winding arrangements are considered: a stacked arrangement, where the windings are wound on multilayers as shown in Fig. 4, and a planar arrangement, where the windings are wound on a single layer as shown in Fig. 5.

In order to assess the benefits of one design over the other, various issues need to be addressed. One of these issues is the ac winding losses within stacked and planar designs. In order to simplify the problem, one-dimensional (1-D) field analysis will be used to calculate the ac resistance of the windings for both designs.

The 1-D field problem can be solved using Maxwell's equations in Cartesian coordinates. Since the current flows only in the $z$ direction and by using the symmetry property of the problem, the only nonzero field component is the $x$ component. As a result, Maxwell's equations can be reduced to the following second-order differential equations:

$$
\begin{aligned}
\frac{d^{2}}{d y^{2}} H_{x} & =j \frac{2}{\delta^{2}} H_{x} \\
\frac{d^{2}}{d y^{2}} J_{z} & =j \frac{2}{\delta^{2}} J_{z}
\end{aligned}
$$

where $\delta$ is the skin depth, which is defined as

$$
\delta=\sqrt{\frac{2}{\omega \mu \sigma}} .
$$


Note here that both the field intensity and the current density are only functions of $y$. In addition, the relationship between $J_{z}$ and $H_{x}$ can be expressed as

$$
J_{z}=-\frac{d}{d y} H_{x}
$$

By combining (1), (2), and (4), the general solution for the magnetic-field intensity is found to have the form

$$
H_{x}=H_{1} e^{k y}+H_{2} e^{-k y}
$$

where $H_{1}$ and $H_{2}$ are constants, which can be evaluated by applying the boundary conditions at the strip boundaries.

Consider a stacked winding arrangement, where a current $I$ is assumed to flow in each of the stack windings. The field distribution within the individual windings is given by (5), while the constants are found by taking amperes circuital law around each conductor. Note here that for the first layer, the field intensity at the lower boundary is zero due to the presence of the high-permeability core. Once the magneticfield intensity is evaluated, the current density distribution and, hence, the ac resistance of each layer can be found. The resultant ac resistance of the $k$ th layer is given by

$$
\begin{aligned}
R_{a c_{-} n}(k)=\frac{1}{2} \cdot\{ & \frac{\sinh \left(a_{n}\right)+\sin \left(a_{n}\right)}{\cosh \left(a_{n}\right)-\cos \left(a_{n}\right)}+(2 k-1)^{2} \\
& \left.\cdot \frac{\sinh \left(a_{n}\right)-\sin \left(a_{n}\right)}{\cosh \left(a_{n}\right)+\cos \left(a_{n}\right)}\right\}
\end{aligned}
$$

where $a_{n}=a / \delta$ is the normalized strip thickness. Note here that the ac resistance is normalized to the dc resistance of one skin-depth-thick conductor. Fig. 6 shows the ac resistance variation of a the strip in each layer as a function of the strip thickness. As shown in this figure, for each layer there exists an optimal thickness for which the ac resistance of the winding is minimal. One interesting observation is that the minima for the first layer (0.92) is quite shallow, and even if a thicker foil is used, little penalty is paid is terms of additional winding losses. In other words, if the operating frequency increases, due to converter modulation, the additional losses induced in the first layer are rather small. This is not the case for the other layers as the minima becomes more pronounced. This means that if the conductors were optimized for a given operating frequency, increasing the frequency can cause significantly higher losses within these windings. In addition, in the presence of a significant dc current component, a thicker foil may need to be used to minimize the dc losses. This will adversely affect the ac resistance of the various layers.

One last issue regarding the stacked winding is the need for different thicknesses for the multilayers to minimize the winding losses. This will complicate the winding terminations and the inductor construction. It is rather easier to use a single thickness for all layers. The effect of having a single thickness for all layers on the total ac resistance of the windings is shown in Fig. 7.

As shown in Fig. 7, there exists an optimal thickness for all layers if a single thickness is used. However, the total losses will be higher in this case compared with having the optimal thickness for each layer. An interesting result of Fig. 7

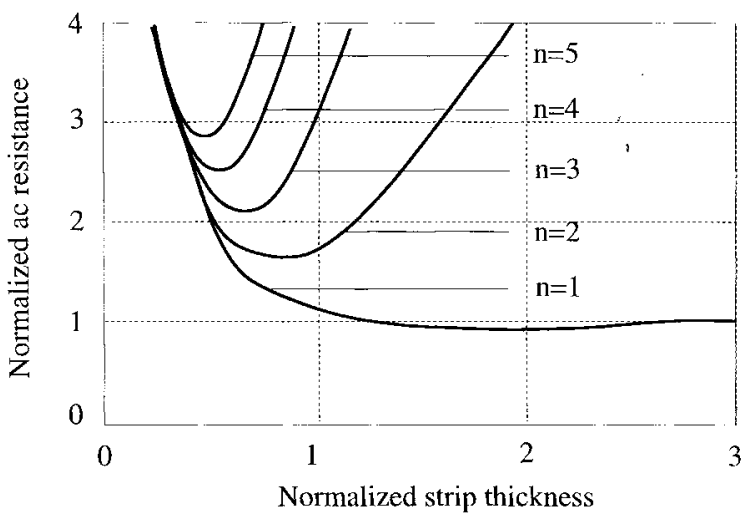

Fig. 6. The ac resistance variation for each layer in a stacked winding arrangement.

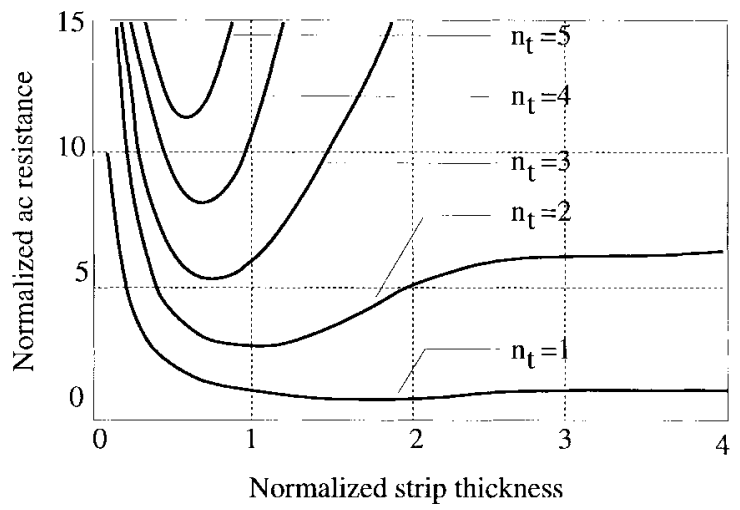

Fig. 7. Total ac resistance of in a stacked winding arrangement with single-foil thickness.

is the fact that the additional resistance penalty with a single thickness for all layers approaches 13\% as the number of turns becomes very large. This is not a significant penalty since the inductor construction and cost can be reduced with a single-layer thickness.

The situation is quite different for a planar winding arrangement. Since the windings are wound on a single layer, the ac resistance of the windings follow the curve given by the first layer of Fig. 6, namely, $n=1$. As a result, all the windings will have the same optimal thickness. In addition, increasing the frequency will have little effect on the losses within the windings, as explained above. This makes it attractive when a dc current component exists since the conductors can be made thicker to minimize the dc losses without much penalty on the ac losses. So, from a winding-loss point of view, it seems beneficial to have a planar winding arrangement rather than a stacked arrangement. The penalty on ac resistance for a stacked design compared with a planar design for the same copper area is shown in Table I.

A second issue regarding both winding arrangements is the core geometry, size, and weight. With a stacked design, the core is narrow and high, while with a planar design, it is wide and short. For example, for a two-turn design and assuming the same copper width for both designs, a planar winding design results in a bigger size core, almost twice as much compared with a stacked design. However, the ac winding losses for 
TABLE I

Comparison of Planar and Stacked Winding Resistance

\begin{tabular}{c|c|c}
\hline Number of turns & $\begin{array}{c}\text { Total nomalized ac } \\
\text { resistance (stacked) }\end{array}$ & $\begin{array}{c}\text { Total normalized ac } \\
\text { resistance (planar) }\end{array}$ \\
\hline 1 & 0.92 & 0.92 \\
\hline 2 & 2.54 & 1.84 \\
\hline 3 & 4.65 & 2.76 \\
\hline 4 & 7.14 & 3.68 \\
\hline 5 & 9.97 & 4.6 \\
\hline
\end{tabular}

the stacked design are $25 \%$ higher compared with the planar design. In fact, if the windings are made narrower by $30 \%$, to have a similar loss figure compared with the stacked design, the penalty on core size is only $50 \%$. In addition, if there exists a significant dc current component, a thicker conductor strip has to be used in order to minimize the dc losses. As a result, the impact on ac losses with a stacked winding will be much higher due to the thicker strips. With a planar design, a thicker conductor strip could be used with the same core size to realize both lower copper and core losses.

The last issue is thermal management. A planar design is much more favorable from a thermal design point of view since all windings are exposed and, hence, can be easily cooled. In a stacked multilayer design, only the outer most layer is exposed and can be cooled efficiently. Using a heat sink does not help the inner most winding since the thermal path is quite long.

In order to quantify the trends discussed above, consider a three turn inductor design for a RDCLI using stacked and planar winding arrangements. The design specifications for the inductor are as follows:

$$
\begin{array}{rlrl}
I_{\mathrm{dc}} & =200 \mathrm{~A}, & & I_{\mathrm{ac}}=50 \mathrm{~A} \mathrm{pk} \\
f_{r} & =75 \mathrm{kHz}, & \Delta f=50 \%
\end{array}
$$

where $f_{r}$ is the resonant frequency and $\Delta f$ is the frequency variation due to the inverter modulation strategy. Since the dc component is a significant portion of the inductor current, the dc losses ought to be minimized. For a stacked winding arrangement and assuming a $1000-\mathrm{A} / \mathrm{cm}^{2} \mathrm{dc}$ current density within copper, for a 1-in-wide strip, the required copper thickness is nearly $30 \mathrm{mil}$. As a result, the dc resistance of the strip is $0.89 \mathrm{~m} \Omega / \mathrm{m}$, which results in $35.6 \mathrm{~W} / \mathrm{m}$ of dc losses. If the same thickness is used for all layers, the resultant optimal thickness at $75 \mathrm{kHz}$ is nearly 0.8 skin depths, namely, $8 \mathrm{mil}$, and the resultant normalized ac resistance of the windings is 5.2 per unit (p.u.) or $13.9 \mathrm{~m} \Omega / \mathrm{m}\left(R_{\delta}=2.67 \mathrm{~m} \Omega / \mathrm{m}\right)$. Since a much thicker conductor is needed to minimize the dc losses, the actual normalized ac resistance of the windings is nearly 20 p.u. or $53.4 \mathrm{~m} \Omega / \mathrm{m}$. As a result, the ac losses are estimated to be $65.4 \mathrm{~W} / \mathrm{m}$, which is almost twice as much as the dc losses.

Assuming the same core size, with a planar winding arrangement, a narrower strip has to be used. In order to keep the dc resistance (losses) the same for both designs, 0.33-inwide 90-mil-thick strips are needed. As a result, the resultant ac resistance of the windings is $24 \mathrm{~m} \Omega / \mathrm{m}$, and the resultant ac losses are $49 \mathrm{~W} / \mathrm{m}$. With a planar winding arrangement, the ac losses are lower by almost $25 \%$ for the same core size. In

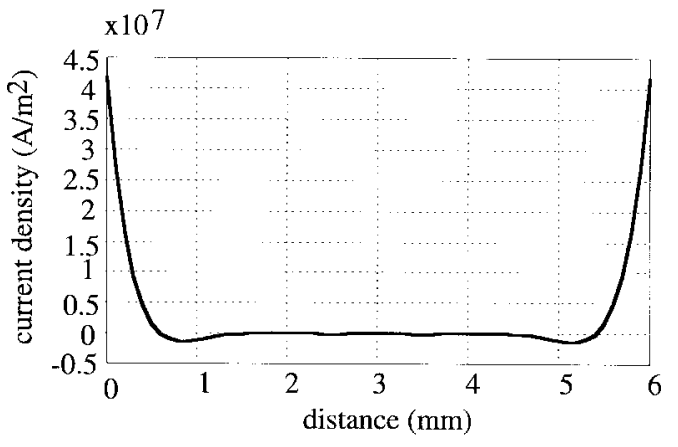

Fig. 8. Current density along a copper strip (in $x$ direction).

fact, the ac losses within a stacked design get even worse if higher number of turns are used. In addition, as the frequency varies, the ac losses in the stacked design get worse, while no penalty is endured in the planar design.

\section{Finite-ELEMENT ANALYSis OF PLANAR COPPER STRIP WINDINGS}

As discussed above, an inductor design with a planar winding arrangement has significant merit compared with a stacked design due to its improved thermal performance under broad-spectrum excitation. In the preceding section, 1-D field analysis was used to quantify the losses within the strip windings. However, due to the two-dimensional (2-D) edge effects, additional losses are induced within the windings. In order to estimate the actual winding losses, finite-element analysis tools are used.

\section{A. Copper Strip in Air}

In order to investigate the 2-D edge effects in strip conductors, consider a copper strip in air as shown in Fig. 8. The strip thickness was assumed to be five skin depths. The strip was analyzed using ANSOFT (a finite-element analysis package). The resultant current density distribution along the strip is also shown in Fig. 8. As shown in this figure, higher current densities exist near the strip edges, which are caused by the perpendicular field component in those regions. This alters the current distribution along the strip and hence increases the induced losses. The actual ac resistance of the strip is higher than that predicted by the 1-D model.

\section{B. The Effect of Magnetic Core}

Since inductor windings are normally wound on a magnetic core, the effect of core on winding losses needs to be investigated. A high-permeability core $\left(\mu_{r} \approx 3000\right)$ material alters the field distribution within the strip and, hence, modifies the current distribution as well. This is due to the fact that the core imposes a zero-field boundary condition on the lower strip surface, which causes a high-field region on the strip upper surface (Fig. 9). Due to proximity effects, the current is attracted to the high-field region and thus, the current crowds near the upper surface of the conductor. This is reflected in the current density plot within the upper conductor as shown in Fig. 10. The ac resistance is higher compared with the previous 


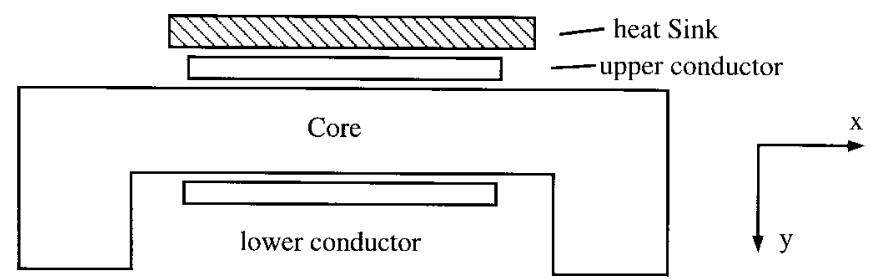

Fig. 9. A copper strip winding on half of a ferrite $c$ core.

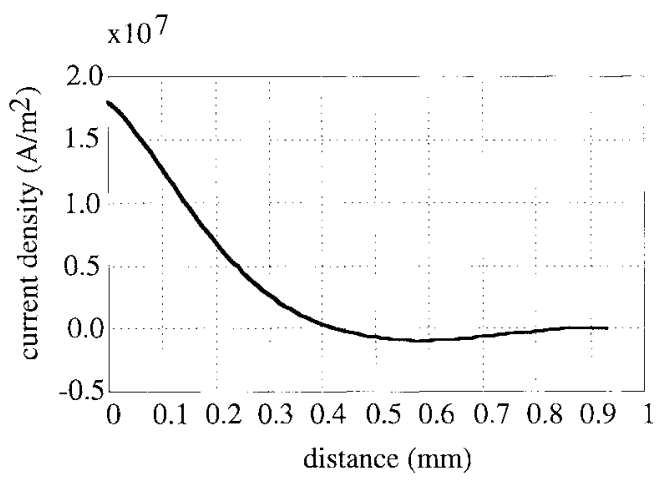

Fig. 10. Current density through copper strip ( $y$ direction) without heat sink.

case since the current flows through a smaller cross-sectional area.

The core does provide a benefit for the lower conductor, which has lower losses compared with the upper conductor. The current density near the edges (next to the vertical core section) is lower than the upper conductor resulting in reduced winding losses. This improvement in current distribution can be attributed to the vertical core legs straightening the field lines that would otherwise pass through the conductor edges. This has a significant impact on the total winding losses.

\section{The Effect of the Heat Sink}

The addition of an aluminum heat sink to improve the thermal capacity of the design affects the distribution of losses as well (Fig. 9). The ac losses of the upper winding are reduced. This is due to the fact that the field produced by the induced currents in the heat sink alter the field near the conductor surface, which affects the current distribution within the strip. However, since a conductive aluminum block is placed in a high-field region, additional losses are induced within the heat sink, thus increasing the total losses. Fig. 11 shows the current density distribution within the upper conductor and the heat sink. As shown in this figure, the current density distribution within the upper conductor is improved compared with Fig. 10, while a significant current is induced within the heat sink causing higher total losses.

\section{Summary of Strip Losses}

In order to summarize the trends described above, the ac losses within the strips for the above three cases were normalized to the strip losses in air and are plotted in Fig. 12. This figure shows that while the addition of a heat sink improves the thermal capacity of the windings, the total losses are increased by $20 \%$. This is due to the induced losses within

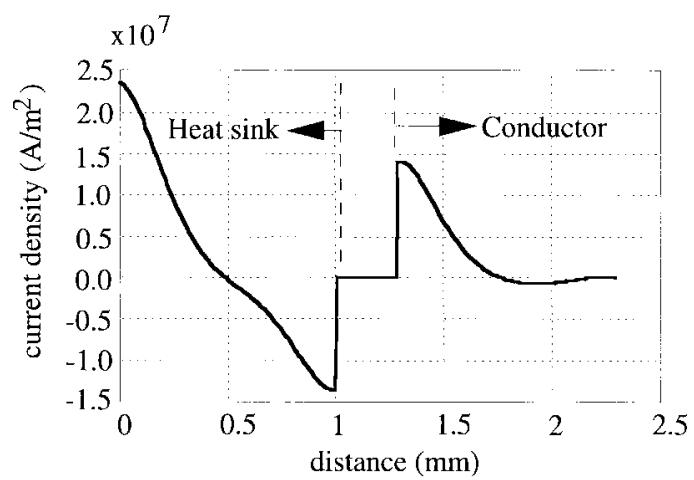

Fig. 11. Current density through upper copper strip and heat sink ( $y$ direction).

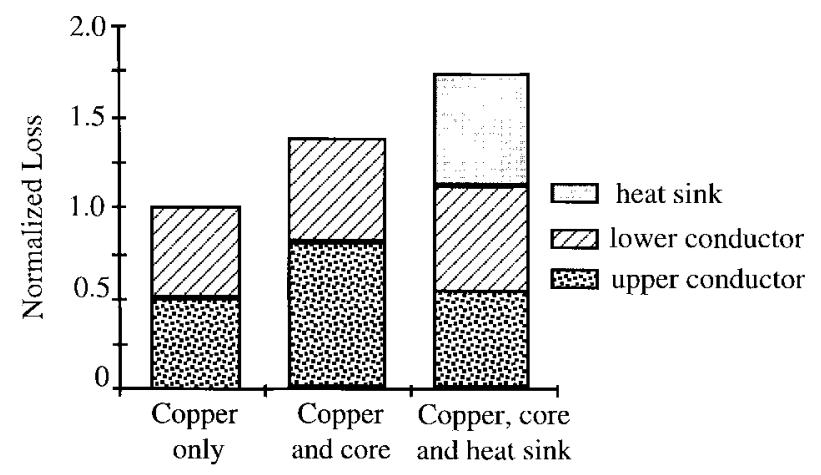

Fig. 12. Comparison of ac winding losses.

the heat sink caused by the placement of a conductive sink in a high-field region. In addition, the lower conductor has lower ac losses due to the straightening of the field lines by the vertical core legs.

\section{Inductor TOPOLOGy CASE Study}

This case study involves a comparison of a uniformly distributed air gap and a ferrite-core inductor design for a 70$\mathrm{kW} 100-\mathrm{kHz}$ RDCLI application. The specifications for the inductor were as follows:

$$
\begin{aligned}
L_{r} & =12 \mu \mathrm{H} \\
I_{\mathrm{dc}} & =230 \mathrm{~A} \\
I_{\mathrm{ac}} & =35 \mathrm{~A} \mathrm{rms} \text { at } 100 \mathrm{kHz} .
\end{aligned}
$$

The ferrite-core inductor is designed with Phillips 3C81 $c$ cores and has four planar turns as shown in Fig. 3(a). The toroidal core inductor is designed with an MPP core with a relative permeability of 16 and has two parallel windings of eight turns each. Table II summarizes the results of both designs. Note here that both analytical and finite-element analysis results were incorporated to compute the winding losses for the ferrite inductor core.

As shown in the above table, the losses are dominated by the dc current component. The ferrite-core inductor design has lower dc losses since the strip windings can be optimized to minimize both ac and dc losses. This is not the case with litz wire. In fact, if the copper strip thickness is doubled, the dc loss is halved with virtually no penalty on inductor size or 
TABLE II

COMParison of the Torroidal AND Ferrite-Core Inductor Designs

\begin{tabular}{l|c|c}
\hline \hline & Toroidal Core & Ferrite Core \\
\hline AC flux density & $0.04 \mathrm{~T}$ & $0.05 \mathrm{~T}$ \\
\hline Core volume & $250 \mathrm{~cm}^{3}$ & $350 \mathrm{~cm}^{3}$ \\
\hline Weight & $2.32 \mathrm{~kg}$ & $1.81 \mathrm{~kg}$ \\
\hline Total core cost & $1.0 \mathrm{pu}$ & $0.45 \mathrm{pu}$ \\
\hline Surface area & $243 \mathrm{~cm}^{2}$ & $388 \mathrm{~cm}^{2}$ \\
\hline Window area & $20.3 \mathrm{~cm}^{2}$ & $10.1 \mathrm{~cm}^{2}$ \\
\hline Current density & $400 \mathrm{~A} / \mathrm{cm}^{2}$ & $1200 \mathrm{~A} / \mathrm{cm}^{2}$ \\
\hline AC copper loss & $9.9 \mathrm{~W}$ & $8.5 \mathrm{~W}$ \\
\hline DC copper loss & $127 \mathrm{~W}$ & $69 \mathrm{~W}$ \\
\hline Heat sink loss & $0 \mathrm{~W}$ & $10.2 \mathrm{~W}$ \\
\hline Core loss & $33 \mathrm{~W}$ & $23 \mathrm{~W}$ \\
\hline Total loss (computed) & $169 \mathrm{~W}$ & $111 \mathrm{~W}$ \\
Total loss (measured) & & $125 \mathrm{~W}$ \\
\hline \hline
\end{tabular}

weight. This is not be true for the toroidal core design. As mentioned earlier, a cost penalty is involved when MPP cores are used. The ferrite-core inductor design reduces the cost by nearly $65 \%$. Finally, the ferrite-core design has significantly larger surface area available for cooling. Hence, the current density can be significantly higher. A $70-\mathrm{kW} 100-\mathrm{kHz}$ ferritecore resonant inductor was designed and built in the laboratory and the experimental measurements match the predicted ones quite well.

\section{CONCLUSION}

1) The main issues governing inductor design for broadspectrum excitation have been identified. These include electrical, thermal, and mechanical issues.

2) Ferrite cores wound with flat copper strips offer reduced winding losses and improved thermal properties compared to toroidal inductors using litz wire.

3) A 1-D analysis using Maxwell's equations was carried out to investigate multiturn windings. It was found that due to the increased ac resistance accrued when windings are stacked, lower overall losses are achieved with a single-layer winding.

4) Finite-element analysis was utilized to estimate the ac copper loss caused by the presence of the core and conductive heat sink. It was found that by adding a heat sink, the winding losses were reduced, but additional losses were induced in the sink. However, by using a heat sink, the losses are transferred to material with more surface area, which can be more easily cooled.

5) A case study showed that it is feasible to design and build an inductor, which has lower loss, more cooling surface area, and a lower cost than the toroidal topology.

\section{REFERENCES}

[1] D. M. Divan, "The resonant DC link converter-A new concept in static power conversion," in IEEE-IAS Conf. Rec., 1986, pp. 648-655.

[2] D. M. Divan and G. Skibinski, "Zero switching loss inverters for high power applications," in IEEE-IAS Conf. Rec., 1987, pp. 627-634.

[3] W. Chou, P. W. Wong, and R. M. Gray, "Dithering and its effects on sigma-delta and multi-stage sigma-delta modulation," in Proc. IEEE ISCAS'90, May 1990, pp. 368-371.

[4] J. D. Lavers, P. P. Biringer, and H. Hollitscher, "A simple method of estimating the minor loop hysteresis loss in thin laminations," IEEE Trans. Magn., vol. MAG-14, pp. 386-388, Sept. 1978.

[5] D. C. Jiles, J. B. Thoelke, and M. K. Devine, "Numerical determination of hysteresis parameters for the modeling of magnetic properties using the theory of ferromagnetic hysteresis," IEEE Trans. Magn., vol. 28, pp. 27-35, Jan. 1992.

[6] M. P. Perry, Low Frequency Electromagnetic Design. New York: Mercel Dekker, 1985.

[7] A. M. Hussein and P. P. Biringer, "Redistribution of current in flat conductors using magnetic bars," J. Appl. Phys., vol. 55, no. 4, Feb. 1984.

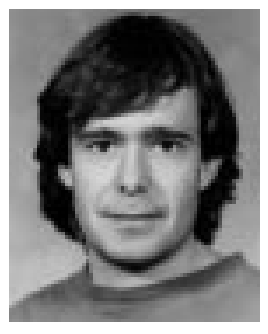

Ian T. Wallace received the B.S. degree in electrical engineering from Penn State University, University Park, PA, in 1989 and the M.S.E.E. degree from the University of Wisconsin, Madison, in 1992.

$\mathrm{He}$ is currently working at Soft Switching Technologies, Middleton, WI, as a Design and Product Development Engineer. His primary research interests include high-frequency magnetics, softswitching power converters, and tackling the myriad of control challenges, which arise in the power conversion field.

Nasser H. Kutkut (M'89), for a photograph and biography, see this issue, p. 66.

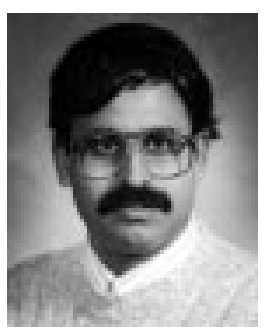

Subhashish Bhattacharya (S'86) received the B.E. (Hons.) degree in electrical engineering from the University of Roorkee, Roorkee, India, in 1986 and the M.E. degree in electrical engineering from the Indian Institute of Science, Bangalore, India, in 1988. He is currently working toward the Ph.D. degree at the University of Wisconsin, Madison.

His primary areas of interest are in active filters, resonant link inverters, utility applications of power electronics, drives, and control techniques.

Deepak M. Divan (S'78-M'83-SM'91), for a photograph and biography, see this issue, p. 178.

Donald W. Novotny (F'87), for a photograph and biography, see this issue, p. 178. 